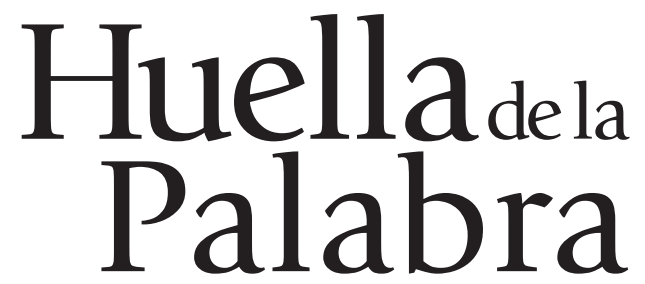

Revista de Investigación Educativa

Universidad La Salle Pachuca

lahuelladelapalabra@lasallep.edu.mx

Teléfono: 01(771) 7170213 ext. 1406

Fax: $01(771) 7170309$

ISSN: En trámite

México

2016

Alfonso Macedo Rodríguez

Notas sobre locura y literatura

Huella de la Palabra, año 2016, número 10

Universidad La Salle Pachuca

pp. $83-90$ 



\section{Notas sobre locura y literatura}

Alfonso Macedo Rodríguez

\section{Resumen}

Este ensayo explora las relaciones entre psicología y literatura a través de algunas representaciones artísticas de la locura en las cuales los personajes asumen una conducta anormal o psicótica que les permite escapar de la realidad, desde Don Quijote y Hamlet hasta Morvan, el detective de Juan José Saer. Asimismo, en el cine esas representaciones actualizan el tema y exploran viejas y novedosas formas en las cuales la mente y la sociedad humanas se extravían.

\section{Abstract}

This essay explores relations between Psychology and Literature across some Madness' Artistic Representations: characters have freak behaviors that allow escape of Reality, from Don Quijote and Hamlet to Morvan, Detective of Juan José Saer. Also at the Cinema these Works modernize and explore old and new Forms where the Human Mind and Society get sick.

El laberinto de la locura es, sin duda, una de las grandes representaciones que la literatura ha explorado por siglos. Los casos más célebres son Don Quijote y Hamlet, que en esta época han sido leídos en diálogo, a propósito del cuarto centenario de los fallecimientos de sus autores (1616).

Más allá de esas efemérides que la industria cultural se ha encargado de poner como nota principal para atraer lectores de suplementos y vender libros, interesa pensar cómo ambos escritores exploran la pérdida de la razón. Por un lado, Cervantes hace que su personaje lea tantos libros de caballerías que pierde la cor-

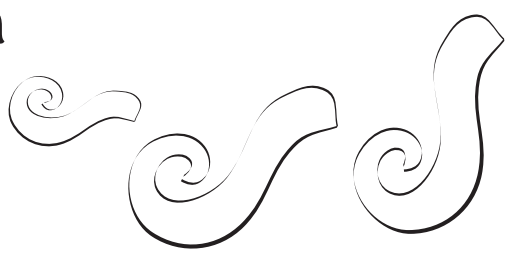

dura; por otro, Shakespeare decide que su héroe se finja loco para poder desenmascarar a su tío. El barroco, como corriente artística vigente en el siglo XVII, expone representaciones dentro de las mismas representaciones ${ }^{1}$ e invierte las nociones de razón y locura: Don Quijote se vuelve loco a causa de la lectura de obras que en su momento causaron la enajenación de sus receptores. Por su lado, Hamlet, que inventa una enfermedad mental, produce un tipo real de locura en su prometida Ofelia, a quien la iconografía moderna sitúa, casi siempre, sumergiéndose en las aguas del río. No es gratuito el guiño intertextual de Lars Von Trier en su película Melancolía (2011), con Justine, vestida de novia, flotando en las aguas del río antes del fin del mundo.

Justamente, la melancolía permite relacionar a Hamlet, Ofelia y Justine: en el filme de Von Trier, la protagonista enferma debido a la aparición del majestuoso planeta Melancolía, que amenaza con chocar contra la Tierra. Su comportamiento y actitud dependen del poderoso astro: se aparta de familiares y amigos para buscar el descanso que, para el filósofo Arthur Schopenhauer, sólo puede ocurrir en el momento de la muerte.

El personaje Hamlet ha sido estudiado por el psicoanálisis. Sigmund Freud y Jacques Lacan se acercaron a esta emblemática figura dramática por su ambigüedad: como ocurre con Don Quijote, en Hamlet hay algo que no permite ser comprendido de manera unívoca, su locura es falsa pero sus acciones están marcadas por la duda, la indecisión y la pusilanimidad.

* Doctor en Teoría Literaria por la Universidad Autónoma Metropolitana-Iztapalapa, catedrático de la Facultada de Ciencias Humanas y de la Escuela de Arquitectura, Diseño Gráfico y Comunicación de la Universidad La Salle Pachuca.

1 En la segunda parte del libro de Cervantes, Don Quijote y Sancho Panza son invitados al palacio de unos duques que han leído la primera parte de la novela; en Hamlet, el príncipe monta una representación teatral para comprobar el crimen de su tío Claudio, creándose, así, una puesta en abismo en la que los espectadores reales asisten a una obra de teatro dentro de otra.

$$
\text { ๑ } 85 \text { @ }
$$




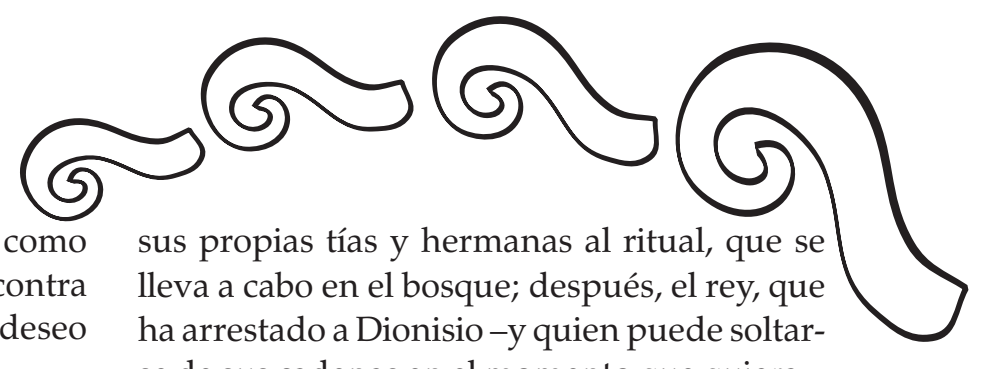

Lacan interpreta las acciones de Hamlet como parte de su complejo edípico: no actuó contra el tío porque éste ya había cumplido su deseo oculto: matar al padre.

Sin embargo, más allá de los estudios psicoanalíticos de Freud que se ocupan de las obras y las biografías de los escritores (Dostoievsky, Shakespeare, Sófocles, Hoffmann, Jensen) para exponer su teoría, en la que los estudios literarios se subordinaron a una visión psicologista, interesa ante todo revisar los modos de representación de la locura sin que necesariamente sean interpretados desde el psicoanálisis.

En este panorama que intentará reflejar algunas conexiones entre locura y literatura, Eurípides es una figura fundamental: contribuyó a la renovación de la tragedia griega. En una época en que la tragedia seguía un canon riguroso, sus aportes impidieron que fuera reconocido en vida, ya que rompía con frecuencia con las unidades de acción, espacio y tiempo, bases de la tragedia clásica. En todo caso, lo importante, aquí, sería ver cómo representa la locura.

En Las bacantes, Eurípides expone con ironía lo que le ocurre a aquellos que dudan del poder de Dionisio. El título de la obra alude a las sacerdotisas de Baco o Dionisio, el dios del vino, quien ha sufrido una especie de olvido por parte de las generaciones jóvenes. En una época en la que predomina la razón como el eje del conocimiento (siglos V y IV a. C), Eurípides les recuerda a sus espectadores que colocar la razón por encima de la irracionalidad podría ser un error. Penteo, rey de Tebas, ha prohibido el culto de Dionisio por considerarlo falso, primitivo y salvaje y ha encarcelado a las bacantes o ménades ${ }^{2}$. Sin embargo, la sorpresiva aparición del dios pondrá en duda el triunfo de la razón: primero, incorporará a se de sus cadenas en el momento que quiera-, sufrirá una crisis de necedad y locura que lo llevará al bosque a interrumpir el ritual. Ahí, las bacantes, entre las que se encuentran las mujeres de su familia, lo someterán a las prácticas del culto más violentas, hasta que es asesinado y descuartizado.

Sin duda alguna, en el culto a Dionisio y Pan (dios del bosque, representado en la iconografía clásica y moderna como un chivo negro, gran cabrón peludo, cuernos y barba) se esconden los deseos más prohibidos de los seres humanos. Fuera de la ciudad, en las antípodas de la civilización, los cultos a estos dioses ofrecen rituales donde todo está permitido: abundancia de comida y vino, orgías, bailes desenfrenados. El bosque, como zona sagrada, es un espacio simbólico totalmente opuesto a la ciudad y a sus jardines perfectamente cuidados, racionales. Así, cuando el cristianismo entra a Europa y la Iglesia Católica se asume como la institución social más poderosa en la Edad Media, era natural que Pan y Dionisio fueran satanizados: sus atributos físicos y psicológicos no eran reconocidos dentro de los valores cristianos y, al no ser comprendidos, fueron atribuidos a lo otro, por lo que se asociaron con el mal y el demonio. Sin embargo, en la religión griega los rituales de estos dioses eran normales y tenían un calendario establecido. De este modo, podemos rastrear en los cultos paganos, llevados a cabo en el bosque, un antecedente directo del sabbath de las brujas en los bosques de la Europa medieval y aún en los Estados Unidos: la aparición de La bruja (2015), del director Robert Eggers, confirma el triunfo de lo irracional, el egoísmo y los prejuicios humanos sobre la razón. Desde la perspectiva racional occidental, la locura y el mal habitan en el bosque.

2 Un cuento que explora el delirio de las bacantes es “Las Ménades” de Julio Cortázar en Final del juego. En ese relato, los músicos y su director, representantes del dios de la música Orfeo, son asesinados por las seguidoras del dios del vino.

$$
\text { ๑) } 86 @
$$




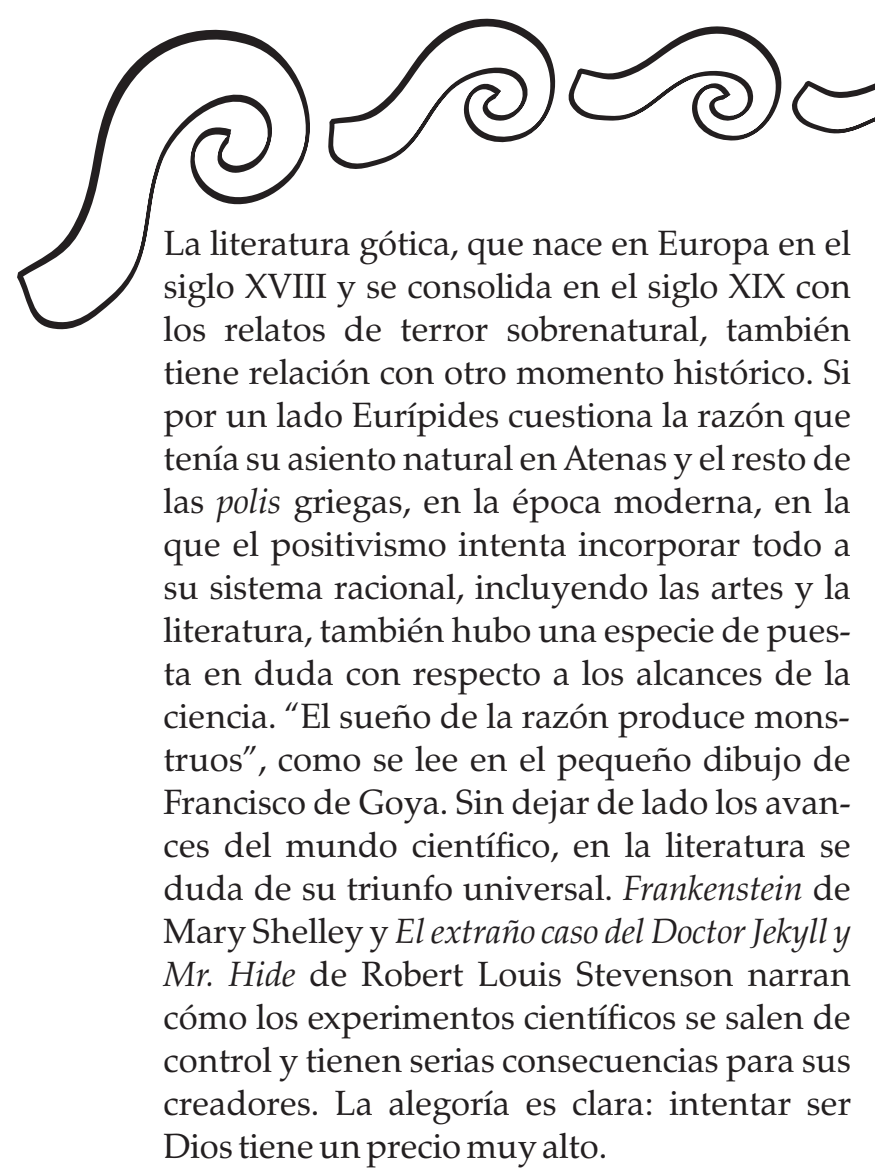

En Latinoamérica hay muchas obras literarias que exploran con gran ironía el tema. Por un lado, El alienista del escritor brasileño Joaquín Machado de Assis trabaja el tema de la locura y sus secuelas. Un médico positivista recibe del gobierno los medios necesarios para crear un manicomio y tiene el poder de decidir quién está loco. Los habitantes del pueblo nunca sabrán cuáles son los síntomas por los que se hacen ganadores a una temporada en el sanatorio. Las causas son múltiples: obsesión por vestir elegantemente, orgullo por poseer una casa magnífica, etc. Poco a poco, el lector asiste a una representación satírica en la que, se concluye, todos están locos, nadie está cuerdo. Machado de Assis, lector de Cervantes, extiende la metáfora de su maestro español y, así como el cura, el barbero y el bachiller Sansón Carrasco, que se disfrazan de caballeros y escuderos para hacer entrar en razón a Don Quijote con el propósito de que regrese a casa y deje de hacer sandeces (lo que sugiere que hay un loco verdadero y hay personas cuerdas que justifican su capacidad de razonar para volverse locas un rato, como un jue- go), así el alienista descubre que el loco más grande es él mismo.

Otros ejemplos de locura en el siglo XIX latinoamericano: el caso del padre Lanzas, del cuento "Lanchitas" de José María Roa Bárcena. El texto, escrito en el contexto del positivismo, igual que El alienista en Brasil, pone en duda la razón, la cultura letrada y la formación intelectual de los sacerdotes, con todos sus latinajos aprendidos de memoria. Considerado uno de los primeros cuentos fantásticos en México, "Lanchitas" narra la transición de un cura que basa sus conocimientos en la inteligencia y la razón, Lanzas, a un loquito al que todos llaman Lanchitas después de un encuentro sobrenatural.

Otro caso similar: el cuento "Un fenómeno inexplicable" del escritor y poeta argentino Leopoldo Lugones, en el que se relata un acontecimiento científico ilógico: la luz de una máquina no proyecta sombras humanas, sino sombras de simios, cuando cualquier persona es expuesta a la luz.

Con los tres ejemplos anteriores, podría decirse que la literatura del siglo XIX refleja un pensamiento cauteloso en relación con los avances científicos y el positivismo. En la literatura del siglo $X X$, las representaciones literarias de la locura serán más ambiguas y no se intenta demostrar, sino sugerir. A los escritores, entonces, les interesarían menos los temas de la locura que los procedimientos artísticos: ¿cómo narrar la locura?

En el ensayo "Literatura y psicoanálisis", del libro Formas breves, el escritor argentino Ricardo Piglia recuerda el encuentro entre Carl Gustav Jung y el grandioso escritor irlandés James Joyce, autor de Ullyses. Joyce estaba preocupado por su hija Lucia debido a la grave crisis que padecía. Sabía que Jung estaba en Suiza y quiso ir a consultarlo. Piglia recuerda que el Dr. Jung había escrito un ensayo sobre la novela de Joyce, así que sabía quién era Joyce y cuáles fueron sus aportes a la nove- 


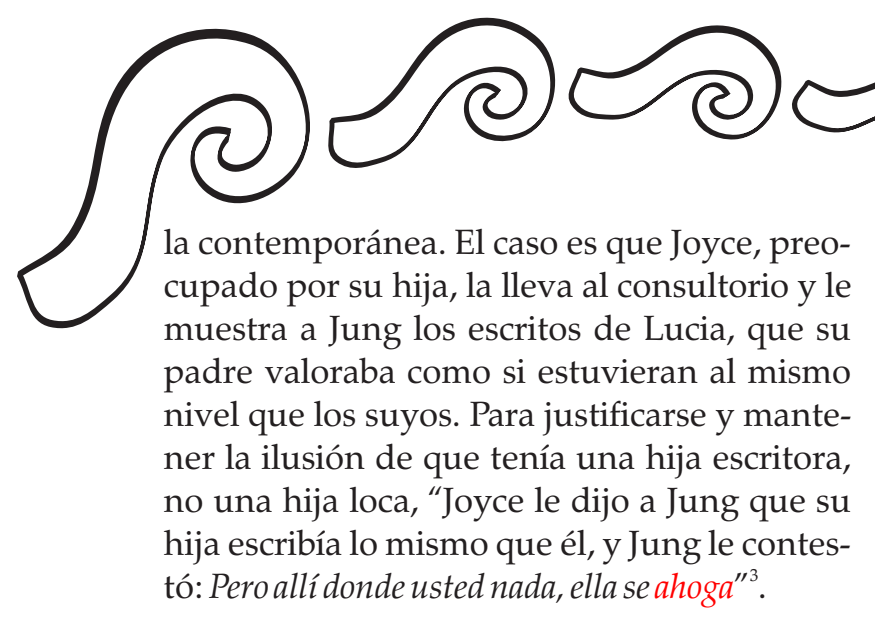

La locura no permite, entonces, tener una sintaxis y un sentido claros. Lucia se pierde en el lenguaje y no puede salir: "Lucia terminó psicótica, murió en 1962 internada en una clínica suiza" ${ }^{\prime 4}$.

Habría que tomar en cuenta otras representaciones de la locura en la literatura y el cine; en este último, también podría pensarse en Relatos salvajes de Damián Szifron, en la que se narran escenas de la vida contemporánea donde la ira, el odio, la venganza y el deseo desembocan en situaciones extremas.

En la literatura contemporánea, los cuentos y las novelas de Enrique Serna, Juan José Saer, Inés Arredondo, Carlos Fuentes y Amparo Dávila reflejan esos estados de inconsciencia en la que los personajes están psicóticos y asumen una doble personalidad ("Tía Nela" de Serna), son fantasmas dominados por la locura y el deseo de hallar un sustituto de su antigua pareja (Aura y "Tlactocatzine, del jardín de Flandes" de Fuentes), son mujeres solteras con deseos sexuales reprimidos que las llevan a la locura ("La señorita Julia" de Dávila) o son rigurosos detectives que de día persiguen al asesino y de noche caen en una especie de insomnio que les hace olvidar lo que hicieron de noche. Tal es el caso de Morvan, protagonista de la novela La pesquisa del escritor argentino Juan José Saer.

La pesquisa narra la ola de asesinatos de ancianas que se lleva a cabo en las calles de París. El detective Morvan es el responsable de la investigación, pero hasta el momento no ha podido encontrar al asesino, quien ha ejecutado brutalmente a diecisiete ancianas. Morvan padece de insomnio, por lo que sus subordinados lo ven, frecuentemente, deambulando perdido por las calles de la ciudad, en plena noche, sin prestarle mucha atención.

Un aspecto fundamental del carácter de Morvan reside en su interés por la mitología griega: desde la infancia, gracias a un libro ilustrado, obsequio de su padre, había conocido la descendencia de los dioses olímpicos, así como la presencia de los monstruos híbridos, alegoría de la pérdida de la razón humana o el poder que tenían antes de la instauración de las leyes civiles. Un leit motiv que cruza la novela son, justamente, los plátanos, símbolo del abuso de un dios sobre una ninfa: se trata del secuestro de Europa, realizado por Zeus en forma de toro blanco:

[...] escrutaba con inquietud las primeras señales de la noche a través de los vidrios helados de la ventana y de las ramas de los plátanos lustrosas y peladas en contradicción con la promesa de los dioses, o sea que los plátanos nunca perderían las hojas, porque fue bajo un plátano que en Creta el toro intolerablemente blanco, con las astas en forma de medialuna, después de haber raptado en una playa de Tiro o de Sidón - para el caso es lo mismo- violó, como es sabido, a la ninfa aterrada. ${ }^{5}$

Los monstruos, mitad bestias, mitad hombres, exigían sangre humana; su poder se extingue con la aparición de los semidioses heroicos, quienes cumplen la misión de proteger a la humanidad. De este modo, algunos relatos de la mitología sugieren la clausura de los rituales religiosos con sacrificios humanos. Sin embargo, La pesquisa también recuerda que los dioses olímpicos, protectores de la humani-

3 Ricardo Piglia, “Literatura y psicoanálisis”, Formas breves, Anagrama, Barcelona, 2001, p. 63.

4 Ibídem.

5Juan José Saer, La pesquisa, Seix Barral, Buenos Aires, 2008, p. 7. 


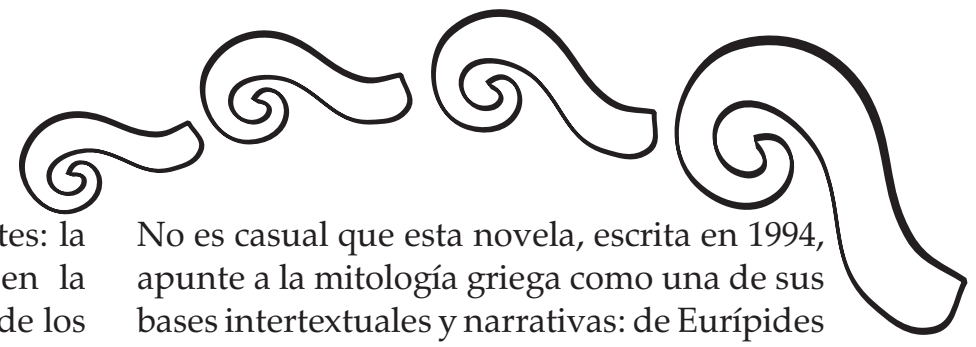

dad, habían ocasionado miles de muertes: la cita anterior, cuyas ideas merodean en la mente de Morvan, indica que el padre de los dioses, en forma de un semental, embarazó a la ninfa que sería madre del rey Minos, quien a su vez padecería el adulterio de su esposa, Pasifae, seducida por un toro en como castigo para Minos por no haber cumplido una promesa de sacrificio a Poseidón. De esa unión zoofílica nace el Minotauro, instrumento de terrorismo empleado contra la ciudad de Atenas. La cita anterior también indica que el abuso sería reparado parcialmente con los frutos eternos del plátano, sin importar la estación del año. Que Morvan observe, en las vísperas de Navidad, los plátanos pelados, sin frutos, indica que los dioses no cumplieron su promesa y siempre habrá acciones impulsadas por deseos sexuales reprimidos, por el triunfo de lo inconsciente y lo irracional.

El sonambulismo de Morvan le impide recordar en qué calles ha andado, sólo tiene conciencia de que está soñando cuando hay signos que no corresponden a la vigilia: una escena recurrente de sus caminatas nocturnas, cuando se encuentra perdido, fuera de los límites de la conciencia y la lucidez, tiene lugar en la zona sede de los poderes institucionales "que se complementan mutuamente" ${ }^{\prime 6}$ : banca, iglesia, escuela, edificio de justicia y estación de televisión. Cuando atraviesa la plaza, dormido pero creyéndose despierto, descubre figuras informes en las estatuas de las plazas vacías, parecidas a animales imaginarios o a seres de una época perdida. Junto a estas formas que conmemoran el poder de lo irracional y celebran "al dios de lo indiferenciado" ${ }^{7}$, también aparecen formas familiares pero siniestras para el comisario: cuando recibe el cambio por el pago de un medicamento, descubre que los billetes no representan a los héroes de la Patria francesa, sino a Medusa, Escila, Caribdis y Quimera.

6 Ibid., p. 161

7 Ibid., p. 109 a los escritores contemporáneos, las representaciones literarias sugieren que el racionalismo humano, triunfo de la filosofía y la ciencia europeas, siempre estará cuestionado por los resortes humanos más ocultos y difíciles de estudiar: la sinrazón y la locura, disparadas por el pensamiento sin que se conozcan las causas, y el deseo, que si se explora sin cuidados lleva al caos y el delirio -como les ocurre a los no iniciados en el rito dionisiaco- $\mathrm{o}$, si se reprime, lleva a la neurosis, esa forma de locura colectiva.
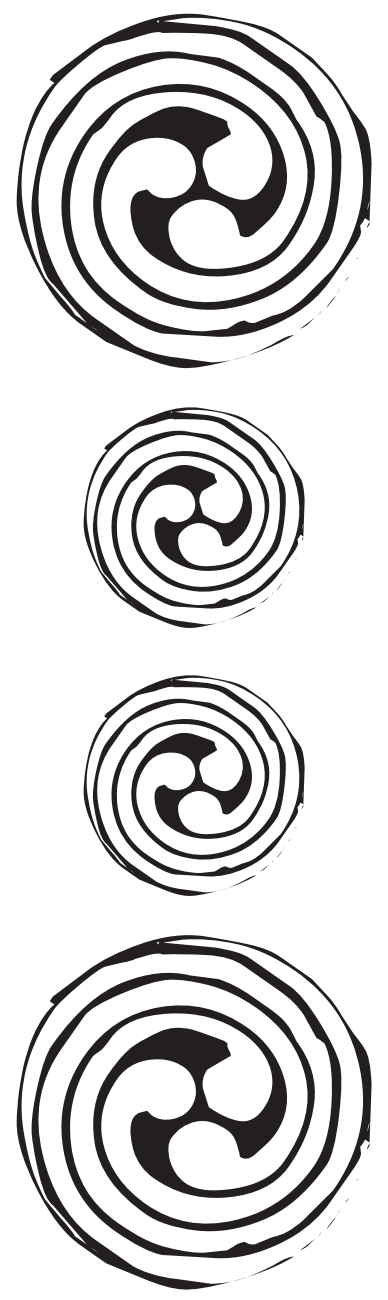


\section{Fuentes de consulta}

Cervantes, Miguel. Don Quijote de la Mancha, I (1987), edición de John Jay Allen, México: REI.

Cortázar, Julio (2001). “Las Ménades”, en Cuentos 1, México: Alfaguara.

Dávila, Amparo (1987). "La señorita Julia”, en Muerte en el bosque, México: SEP/FCE.

Eurípides (2000). Las Bacantes, en Tragedias III, Edición de Juan Miguel Labiano, Madrid: Cátedra.

Fuentes, Carlos (1998). Aura, México: Era.

------- (1998). “Tlactocatzine, del jardín de Flandes", Los días enmascarados, México: Era.

Lugones, Leopoldo (1997). “Un fenómeno inexplicable”, en Óscar Hahn, (selección, prólogo y notas), Antología del cuento fantástico hispanoamericano. Siglo XX, Santiago de Chile: Editorial Universitaria.

Machado de Assis, Joaquín (2008). El alienista, trad. de Agustín Trefogli, México: Axial

Piglia, Ricardo (2001). Formas breves, Barcelona: Anagrama.

Roa Bárcena, José María (2013). “Lanchitas”, en Bernardo Esquinca y Vicente Quirarte, Ciudad fantasma. Relato fantástico de la Ciudad de México [XIX-XXI], T. I, Oaxaca, Almadía.

Saer, Juan José (2008). La pesquisa, Buenos Aires: Seix Barral.

Serna, Enrique (1999). “Tía Nela”, El orgasmógrafo, México: Plaza Janés.

Shakespeare, William (2009). Hamlet, prólogo de Vicente Molina Foix, Madrid: Alianza.

\section{Filmes}

Eggers, Robert (2015). The Witch, Estados Unidos-Canadá; Universal Pictures.

Szifron, Damián (2014). Relatos salvajes, Argentina; ICAA/El Deseo

Trier, Lars Von (2011). Melancholia, Francia-Italia-Suecia-Alemania-Dinamarca; Zentropa International.
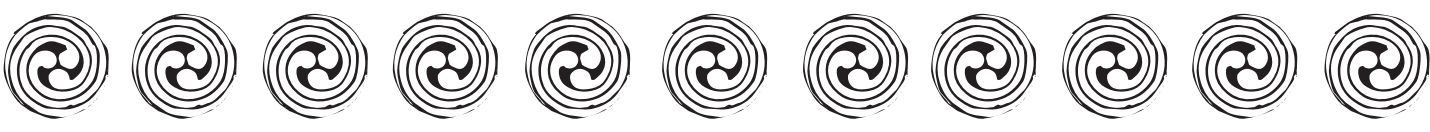

๑90@ 